\title{
Snow avalanche runout from two Canadian mountain ranges
}

\author{
D. J. Nixon AND D. M. MaClung \\ Department of Civil Engineering, University of British Columbia, Vancouver, B.C., Canada V6T 1Z4
}

\begin{abstract}
Field measurements on maximum runout from two different mountain ranges in Canada are presented and compared: the Coast Mountains in British Columbia and the Rocky Mountains. We include a statistical analysis of topographic terrain parameters such as starting zone catchment area, horizontal reach, vertical drop and relevant slope angles. Following McClung and Mears (1991), we derived a dimensionless parameter which is a measure of runout for each avalanche and we found that the runout ratios (defined below) for a given mountain range obey a Gumbel distribution consistent with previous results. In addition, we found that the runout ratios for both mountain ranges have a length-scale dependence which is potentially very important for land-use planning procedures: the mean value of the runout ratio decreases significantly as the horizontal reach increases. Together with data from other mountain ranges, our results show that path length effects will have to be incorporated when using statistical prediction methods for engineering zoning purposes.

The runout ratio is defined as the quotient of two lengths, $\Delta x / X_{\beta}$, where $\Delta x$ is the horizontal distance from the $10^{\circ}$ point to the maximum runout position, and $X_{\beta}$ is the horizontal distance from the start position to the point where slope angle first declines to $10^{\circ}$.
\end{abstract}

\section{INTRODUGTION}

The engineering aspects of zoning in snow avalanche terrain include: (1) prediction of runout distances and (2) specification of expected impact forces if structures are to be placed in danger zones. It is not currently possible to predict runout distances in a deterministic sense by selecting friction coefficients in a dynamic model because the problem is too complex and the errors cannot be defined. The only alternative yet proposed is to specify runout distances by a statistical definition of runout position for a mountain range in terms of topographic parameters.

In this study, new data obtained from the southern British Columbia Coast range are analyzed with the regression methods of topographic features (Lied and Bakkehöi, 1980) and the extreme-value runout ratio model of McClung and Mears (1991). McClung and Mears found that runout distances obey a Gumbel distribution which is frequently used for describing extreme values for other natural hazards. In addition, the data from two Canadian mountain ranges, the Rocky Mountains and the British Columbia Coast Mountains, are compared using the two statistical methods. The benefit of a statistical model is that the errors in runout distances are quantified in standard statistical terms. For example, when the consequences of an avalanche are unacceptable a conservative margin of safety is desirable.

We employ the method of multiple regression analayses of topographic parameters (Lied and Bak- kehøi, 1980) to discover practical and definable predictors of avalanche runout distances. As other studies show (McClung and Mears, 1991), terrain parameters such as aspect, reach, slope length and start-zone angle carry little or no significance in predicting the response variable of the regression model.

The length-scale effect observed in the Colorado Rockies data (McClung and Mears, 1991) is also detected in both the Rocky Mountains and the British Columbia Coast Mountains. Partitioning the data provides a method of improving the predictive equation for runout distance.

Finally, the least squares regression model is compared to the runout ratio model. The comparison shows that the latter is superior for predicting runout distances based on engineering criteria.

\section{DESCRIPTIVE STATISTICS}

For this study, we collected new data from the Coast Mountains of British Columbia by the methods discussed by Lied and Bakkehöi (1980) and McClung and others (1989). All maximum runout locations are determined from vegetation damage limits in mature forests. Core samples from trees bordering the maximum runout zone ranged in age from 50 to 250 years (approximate average around 100 years). The random error introduced by this variation should diminish as the number of avalanche paths surveyed increases, according to McClung and Mears (1991), and they found that 30 avalanche paths 


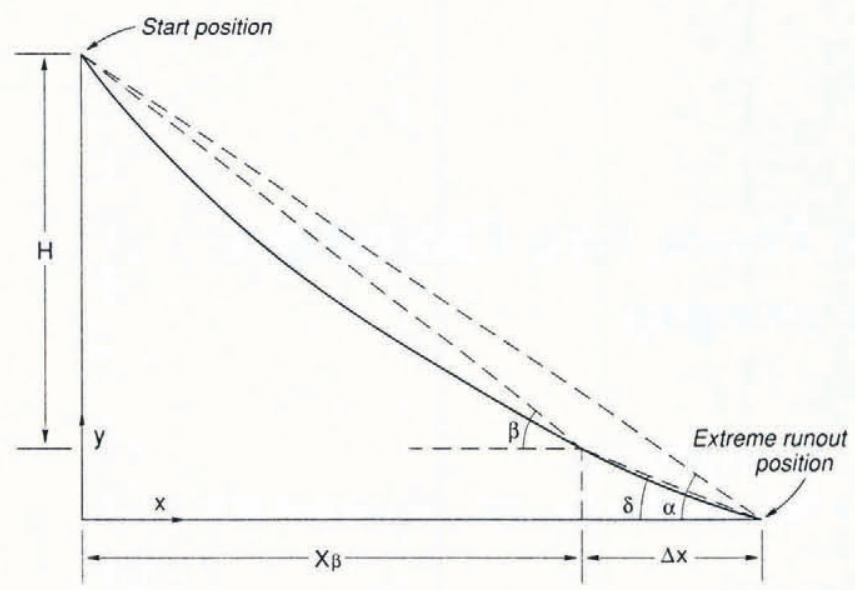

Fig. 1. Definition of geometry and angles to determine extreme runout.

were the minimum required to perform an analysis.

As with previous studies, we defined terrain parameters from our data. The angle alpha $(\alpha)$ is defined by sighting from the extreme avalanche runout point $(\alpha \cdot)$ to the top of the avalanche start zone. The angle beta $(\beta)$ is defined by sighting from the position where the slope angle first declines to $10^{\circ}(\beta \cdot)$ to the avalanche start zone. The beta point $(\beta \cdot)$ is a reference point from which runout distance $(\Delta x)$ is calculated. The angle delta $(\delta)$ is defined by sighting between the $\alpha$. and the $\beta$. The field data measured consist of two angles: alpha $(\alpha)$ and beta $(\beta)$ (see Figure 1) and a slope profile surveyed from the beta point $(\beta \cdot)$ to the alpha point $(\alpha \cdot)$. The runout distance $(\Delta x)$ is the horizontal distance between the $\beta$. and the $\alpha$. The vertical displacement $(H)$ is measured between the $\beta$. and the avalanche start zone. The surveyed slope profile allows the calculation of $\Delta x$ and angle $\delta$. The reach $\left(X_{\beta}\right)$ is the horizontal distance between the start zone and the $\beta$.

The runout ratio is a dimensionless parameter (McClung and others, 1989) defined as:

$$
\frac{\Delta x}{X_{\beta}}=\frac{\tan \beta-\tan \alpha}{\tan \alpha-\tan \delta} \text {. }
$$

The mean, standard deviation and range of the variables used are presented in Table 1.

\section{THE REGRESSION MODELS}

Data from the two mountain ranges were analyzed with least squares regression techniques to obtain models of the form $\alpha=C o \cdot \beta+C 1$ (Lied and Bakkehöi, 1980). The following equations are obtained ( $\wedge$ denotes predicted value):

Rocky Mountains : $\hat{\alpha}=-0.784+0.956 \cdot \beta$

$\left(R^{2}=0.75, \mathcal{N}=126, S e=1.75\right)$ where $R^{2}$ is the coefficient of determination and $\mathrm{Se}$ is the standard error.

Coast Mountains : $\hat{\alpha}=-1.395+0.954 \cdot \beta$

$\left(R^{2}=0.74, \mathcal{N}=31, S e=1.70\right)$. In both cases the constant $C 1$ is not significant: the t-statistics are -0.52 and -0.45 , respectively, compared with t-statistics for $\beta$ of 19.1 and 9.1, respectively. These results are in agreement with the results of McClung and Mears (1991) indicating that $\beta$ is usually the only significant parameter.

A statistical test of the mean $\alpha$ angles from the two mountain ranges results in acceptance of the null hypothesis that the two means are equal. This implies that the mean runout distances, calculated from the least squares equation, are also equal by the theorem that "any

Table 1. Descriptive statistics for the Canadian Rocky Mountains and the Coast Mountains of British Columbia

Mean Standard deviation $\begin{gathered}\text { Range of values } \\ \text { minimum }\end{gathered}$

Canadian Rockies and Purcells

$\begin{array}{lccccc}\alpha & 27.8 & 3.5 & 20.5 & 40.0 & 127 \\ \beta & 29.8 & 3.1 & 23.0 & 42.0 & 126 \\ \delta & 5.5 & 5.3 & -21.5 & 20.6 & 125 \\ H(\mathrm{~m}) & 869 & 268 & 350 & 1960 & 124 \\ \Delta x & 168 & 131 & -190 & 524 & 124 \\ \Delta x / X_{\beta} & 0.114 & 0.100 & -0.185 & 0.404 & 125\end{array}$

Coast Mountains of British Columbia

$\begin{array}{lccccl}\alpha & 26.8 & 3.3 & 20.4 & 32.5 & 31 \\ \beta & 29.5 & 3.0 & 22.8 & 34.0 & 31 \\ \delta & 5.5 & 3.6 & -5.0 & 14.1 & 31 \\ H(\mathrm{~m}) & 903 & 313 & 426 & 1915 & 31 \\ \Delta x & 229 & 202 & 0 & 1150 & 31 \\ \Delta x / X_{\beta} & 0.159 & 0.115 & 0.000 & 0.559 & 31\end{array}$


linear combination of independent normal random variables is also normally distributed" (Neter and others, 1982). A similar statistical test performed on the means of $\Delta x$ for both ranges verifies that they are also similar with high significance. This suggests that the regression models for both ranges are interchangeable and that there are no significant differences in terrain features. However, when the problem is analyzed by fitting runout distances to an extreme-value distribution, this conclusion must be altered.

Other topographic features were added to assess their significance in a multiple regression model. Some of the variables used are: area of catchment $(A C)$, aspect $(\beta)$, slope distance $(S 2)$, start zone angle $(\theta)$, vertical displacement $(H)$, and horizontal reach $\left(X_{\beta}\right)$. Slope distance is defined as $X_{\beta} / \sin \beta$. The regression model tested for both mountain ranges was of the form

$$
\hat{\alpha}=f\left(C 1, A C, \text { aspect }, \beta, S 2, \theta, X_{\beta}, H\right) .
$$

When comparing the multiple variable model to the single variable model it was found that additional topographic variables were not significant (Table 2): the angle $\beta$ is the only variable with a highly significant t-statistic. For the Rocky Mountains, aspect is a significant, but not highly significant, variable, and it is not significant at all in the Coast Mountain analysis. Further analysis of other ranges is required to determine whether aspect should be included as a significant predictor variable. Since the accuracy of field measurements is $\pm 0.5^{\circ}$ and the improvement in the predicted angle is less than this error, there is no benefit in including additional topographic variables. This conclusion is strengthened by examination of the marginal improvement in the coefficients of determination and the standard error of estimate.

Other combinations of parameters, such as those used by Lied and Bakkehöi (1980), produce similar results: the additional parameters only serve to provide over-fitted equations without significantly reducing the standard error or improving the prediction.

Table 2. Multiple regression statistics. Se is the standard error of estimate; $R^{2}$ is the coefficient of determination

\begin{tabular}{|c|c|c|}
\hline \multirow[b]{2}{*}{ Variable } & \multicolumn{2}{|c|}{ t-statistics } \\
\hline & Coast Mountains & Rocky Mountains \\
\hline & $\begin{array}{l}R^{2}=0.78 \\
S e=1.65\end{array}$ & $\begin{array}{l}R^{2}=0.78 \\
S e=1.64\end{array}$ \\
\hline
\end{tabular}

\begin{tabular}{lrc}
$C 1$ & -1.4 & 0.8 \\
$A C$ & -0.8 & -1.2 \\
aspect & 0.7 & 2.2 \\
$\beta$ & 3.8 & 5.0 \\
$S 2$ & -1.4 & 1.6 \\
$\Theta$ & -0.6 & 0.05 \\
$X_{\beta}$ & 1.4 & -1.5 \\
$H$ & -0.1 & 0.3 \\
\hline
\end{tabular}

\section{EXTREME-VALUE MODELS}

McClung and Mears (1991) analyzed extreme runout from more than 500 avalanche paths from five different mountain ranges. Their results showed that a set of extreme runout ratios from a mountain range may be assumed to obey a Gumbel distribution.

Assuming that the runout distance should conform to an-extreme-value distribution, McClung and others (1989) proposed fitting a dimensionless runout ratio (Equation (1)) to a Gumbel distribution. In simplest form, a least squares fit to the data takes the form

$$
X p=u+b \cdot Y,
$$

where $[p]$ is the non-exceedance probability, $Y$ is the reduced variate $(Y=-\ln [-\ln [\mathrm{p}]), u$ and $b$ are location and scale parameters, respectively, and $X p$ is the runout ratio $\Delta x / X_{\beta}$ for the chosen non-exceedance probability.

Table 3. Location (u) and scale (b) parameters

\begin{tabular}{cccccc}
\hline & $u$ & $b$ & Se & $R^{2}$ & $\mathcal{N}$ \\
\hline $\begin{array}{c}\text { Rocky Mountains } \\
\text { (censored) }\end{array}$ & 0.079 & 0.070 & 0.012 & 0.98 & 79 \\
$\begin{array}{c}\text { Coast Mountains } \\
\text { (censored) }\end{array}$ & 0.096 & 0.092 & 0.021 & 0.96 & 20 \\
$\begin{array}{c}\text { Coast Mountains } \\
\text { (uncensored) }\end{array}$ & 0.107 & 0.088 & 0.020 & 0.97 & 31 \\
\hline
\end{tabular}

Location and scale parameters for the two mountain ranges are given in Table 3 . To illustrate the differences in mountain ranges, the data and the regression lines for the two ranges are presented in Figure 2. In Table 3, the data for the Rockies were censored at $p=e^{-1}$ to provide a least squares fit on the tail of the distribution where engineering applications predominate. The Coast Mountains runout ratios are presented both for censored data $\left(p=e^{-1}\right)$ and uncensored data. For the Coast range, the resulting differences in $\Delta x$ are no more than $1-2 \%$ for both relationships. Therefore, the effect of censoring the Coast Mountains data (reducing the sample size to 20 paths) is minimal.

A comparison of the runout ratios from six mountain ranges is contained in Table 4 for $p=0.99$ and $p=0.80$ based upon the Gumbel parameters provided by McClung and Mears (1991). The runout ratios for Norway and the Coast Mountains of British Columbia are the most similar, whereas the data from the Canadian Rockies give the lowest ratios. This trend also applies to the mean values of $\Delta x$ for these three ranges. The effect of climate regime is not apparent in the data represented in Table 3 (McClung and others, 1989). For example, the Colorado Rockies and the Canadian Rockies are both in continental climates, yet the former have the longest runout distances while the latter have the shortest. 


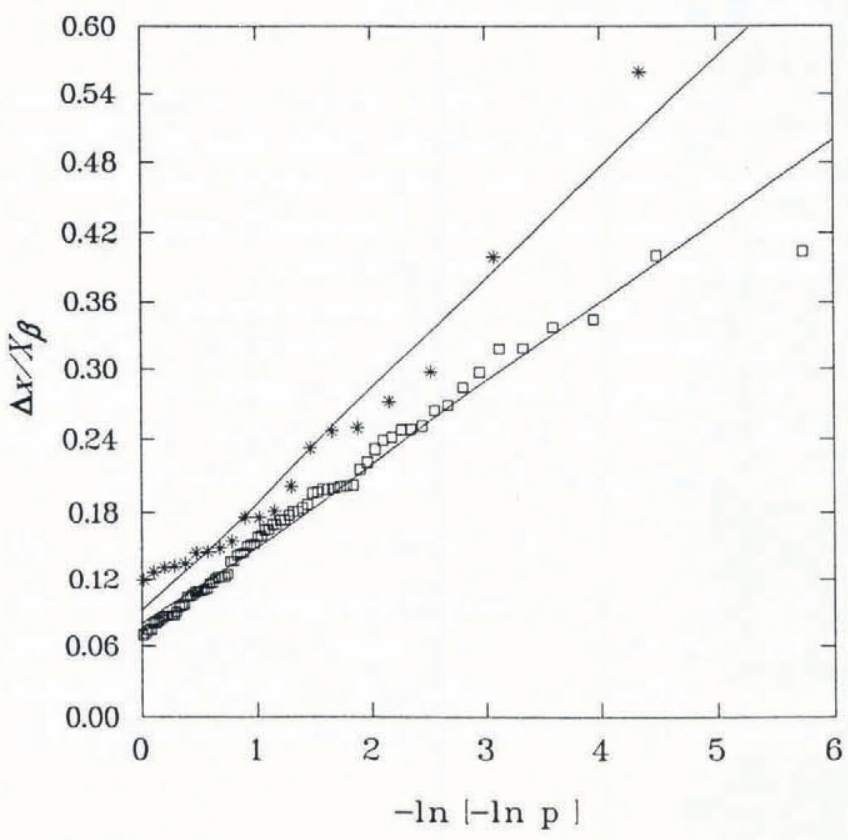

Fig. 2. Data from the Rocky Mountains and Coast Mountains of British Columbia censored at $p=e^{-1}$. * denotes Coast Mountains; $\square$ denotes Rocky Mountains.

\section{LENGTH-SCALE EFFECTS}

McClung and Mears (1991) highlighted the importance of length-scale effects for data from the Colorado and Sierra Nevada ranges. Similar effects were also present for both Canadian ranges. To investigate the effect of lengthscale on runout ratios, runout ratio models were fitted to the arbitrarily partitioned data (see McClung and Mears, 1991). Two Gumbel relationships were derived by partitioning at $X_{\beta}=1500 \mathrm{~m}$ for the Rocky Mountains and $X_{\beta}=2100 \mathrm{~m}$ for the Coast Mountains data. The plot of runout ratio vs $X_{\beta}$ illustrates the length-scale effect for the Rockies (Fig. 3). With partitioning and $p=0.99$, the Rocky Mountains runout distances are 15\% higher than the non-partitioned model if $X_{\beta}<1500 \mathrm{~m}$ and $28 \%$ lower if $X_{\beta}>1500 \mathrm{~m}$. This result is very important for planning and land use decisions. The length-scale effect also appears in the Coast Mountain data; however, more data are needed to quantify the relationships.

Table 4. Runout ratios for non-exceedance probabilities

$$
\text { Mountain range } \quad p=0.99 \quad p=0.80
$$

\begin{tabular}{lll}
$\begin{array}{l}\text { Canadian Rockies } \\
\text { and Purcells (censored) }\end{array}$ & 0.401 & 0.184 \\
$\begin{array}{l}\text { British Columbia } \\
\text { Coast Mountains }\end{array}$ & 0.512 & 0.239 \\
Western Norway & 0.497 & 0.258 \\
Coastal Alaska & 0.682 & 0.347 \\
Colorado Rockies & 1.217 & 0.591 \\
Sierra Nevada & 1.32 & 0.683 \\
\hline
\end{tabular}

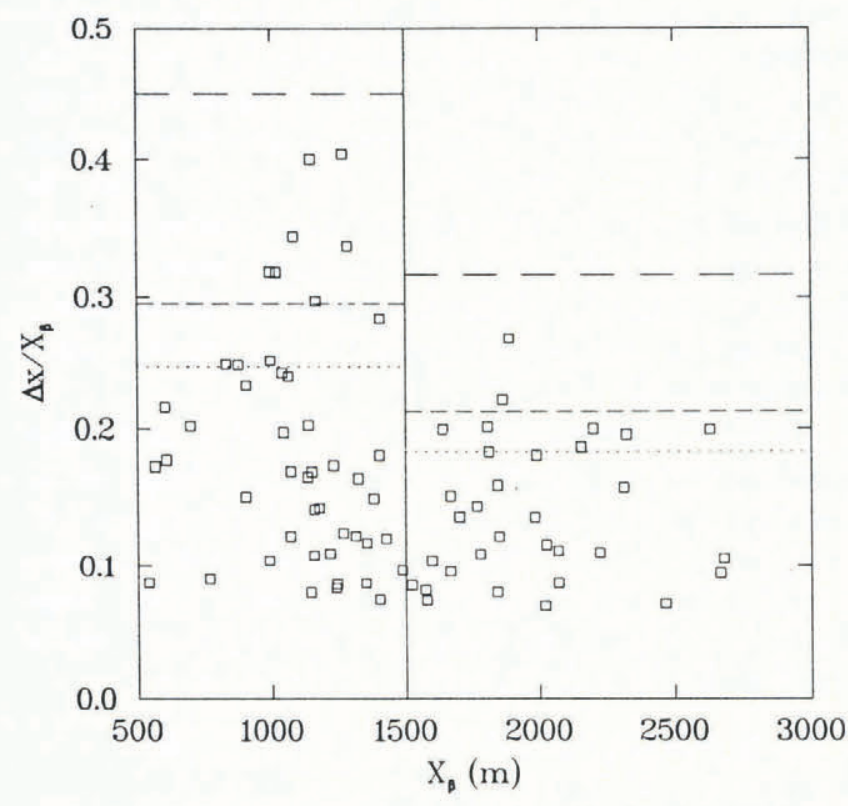

Fig. 3. Data from the Canadian Rocky Mountains partitioned at $X_{\beta}=1500 \mathrm{~m}$. The three lines represent three values of the non-exceedance probability $(--\longrightarrow, p=0.99),(---, p=0.90)$, (....,p 0.80$)$.

The data in Figure 3 suggest that runout ratio is inversely proportional to $X_{\beta}$. However, a least squares analysis of the form $\Delta x / X_{\beta}=C 1+C o \cdot X_{\beta}^{-1}$ has a low coefficient of determination $\left(R^{2}=0.044\right)$ and the constant $C 1$ has the only significant t-statistic (5.4). More sophisticated methods of regression might reveal a better relationship for the data in Figure 3; however, partitioning the data and using the Gumbel distribution are simple and effective methods of improving the estimates for avalanche zoning.

\section{COMPARISON OF REGRESSION AND GUMBEL DISTRIBUTION METHODS}

Following the work of Lied and Bakkehöi (1980) many people still use the least squares approach for runout positions. In this section, we provide a comparison of the least squares and Gumbel statistics methods. The regression model (least squares) contains the assumption that the runout distances are approximately normally distributed. A least squares fit of the data allows the prediction of an $\alpha$ angle as a function of a non-exceedance probability for comparison with the Gumbel predictions. The data in Table 5 allow comparison of the two models for seven avalanche paths chosen randomly from the Rocky Mountains. For the regression model, runout distance $(\Delta x)$ is calculated from $\alpha_{p}, \beta, H$, and $X_{\beta}$.

The runout ratio model contains the assumption that runout distances fit a Gumbel distribution. A least squares fit of plotting positions (McClung and Mears, 1991) gives a linear equation which predicts a dimensionless runout ratio (Equation (4)) for a given non-exceedance probability. Runout distance $(\Delta x)$ is calculated by multiplying $X_{p}$ and $X_{\beta}$.

When both models are compared at the median 
Table 5. Comparison of runout distances $(\Delta x)$ for seven avalanche paths selected at random from the Rocky Mountains for the regression model $\alpha_{\mathrm{p}}=-0.784+0.956 \cdot \beta$ and for the runout ratio model $X_{\mathrm{p}}=0.07+0.076(-\ln [-\ln p])$

Regression model

Avalanche path

$$
p
$$

$\alpha_{\mathrm{p}}$

Predicted $\Delta x$

number

$\mathrm{m}$

29.7

31.7

32.4

33.8

35

69

71

87

100

\subsection{0 \\ 0.50}

\subsection{9}

0.90

0.80

0.50

0.99

0.90

0.80

0.50

0.99

0.90

0.80

0.50

\subsection{9}

0.90

0.80

0.50

0.99
0.90

0.80

0.50

0.99

0.90

0.80

0.50
20.0

22.0

22.7

24.1

22.9

24.9

25.6

26.9

23.3

25.3

26.0

27.4

20.9

22.9

23.6

25.0

21.4

23.4

24.1

25.5

24.3

26.3

27.0

28.4

\section{1}

237

195

117

732

437

349

192

343

204

161

107

375

226

182

104

461

287

232

130

1095

645

513

278

306

193

157

90
Runout ratio model

$X_{\mathrm{p}} \quad$ Predicted $\Delta x$

$\mathrm{m}$

$\begin{array}{ll}0.420 & 436 \\ 0.241 & 251 \\ 0.184 & 191 \\ 0.098 & 102\end{array}$

0.420

699

0.241

402

0.184

307

0.098

163

$0.420 \quad 475$

$0.241 \quad 273$

$0.184 \quad 208$

$0.098 \quad 111$

$0.420 \quad 429$

$0.241 \quad 246$

$0.184 \quad 188$

$0.098 \quad 100$

$0.420 \quad 642$

$0.241 \quad 369$

$0.184 \quad 281$

$0.098 \quad 150$

$0.420 \quad 923$

$0.241 \quad 530$

$0.184 \quad 405$

$0.098 \quad 215$

$0.420 \quad 428$

$0.241 \quad 246$

$0.184 \quad 187$

$0.098 \quad 100$

$(p=0.5)$ of both distributions (Fig. 4$)$ the runout ratio model predicts shorter runout distances. However, at higher values of $p$ the opposite is true: the Gumbel model is consistently more conservative.

\section{SUMMARY AND DISCUSSION}

In this paper, we examine and compare two methods of predicting runout distances: least squares regression of topographic parameters and the runout ratios fitted to a Gumbel distribution. Analysis of the British Columbia Coast Mountains data with the least squares method showed that the angle $\beta$ is the only significant parameter for predicting the $\alpha$ angle. Other topographic terrain parameters were not significant and do not improve the predicted angle more than the data error. In addition, analysis of the data from the British Columbia Coast range shows that runout ratios obey a Gumbel distribution. Statistical tests confirm that the least squares regression parameters for the Coast range and the Rocky Mountains are similar while those for the runout ratio models are significantly different. As a result, when Gumbel statistics are employed it is important that the runout ratio parameters for one range not be used for another.

Our most important result comes from the comparison of the two models using the same data. Specifically, the 


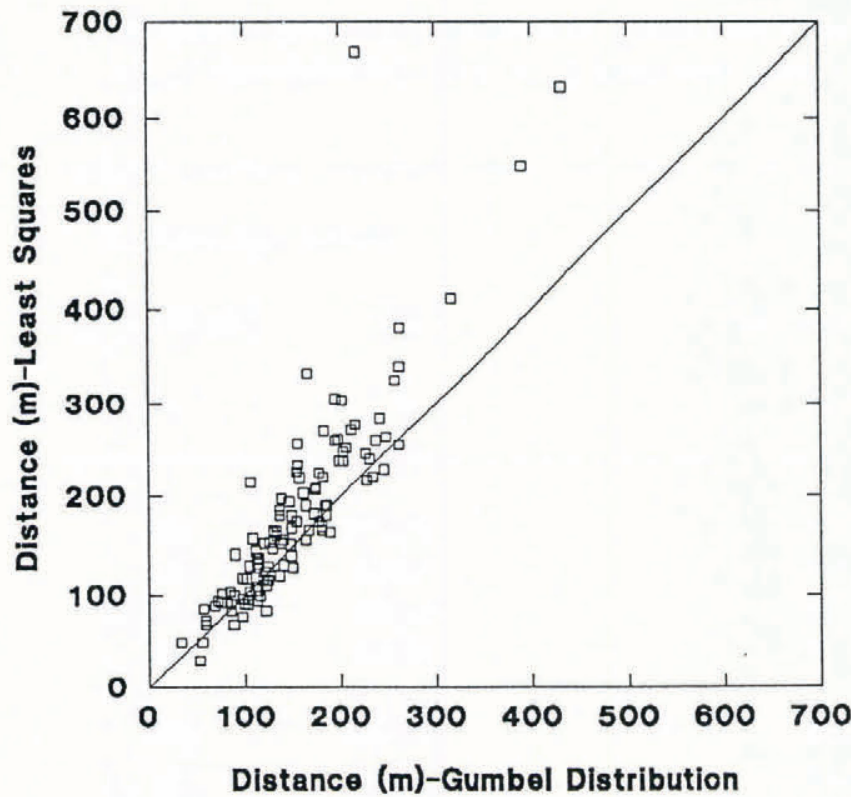

Fig. 4. Comparison of runout predictions for the Rocky Mountains for the least squares (Equation (2)) and Gumbel distribution (see Table 3) at $p=0.5$.

runout ratio model predicts longer runout distances than the regression model in the zone of engineering applications. The differences in runout distances between models increase as the probability of non-exceedance increases. Furthermore, the errors for the regression model (and hence runout predictions) are assumed to be approximately normally distributed in a least squares model. However, our analysis shows that the runout ratios (and distances) obey a Gumbel distribution.

Length-scale effects have now appeared in runout data from several mountain ranges (including the Rocky Mountains and Coastal Mountains in British Columbia). Unless it is properly accounted for, this condition may lead to large errors in estimating runout distances. One method, which we have illustrated, is partitioning at significant divisions in the data with separate derivations for data above and below the dividing horizontal reach. This is not entirely satisfying since the dividing line is arbitrarily chosen. In addition, a larger data set is rquired when length-scale effects are present to avoid sample size effects. Although the method of partitioning is simple to employ, perhaps in the future more sophisticated methods can be explored.

We believe, based on data analysis from over 500 avalanche paths, that the runout ratio model is superior to the least squares regression of topographic parameters for estimating safe runout distances. The implication is that long runout distances obey a Gumbel distribution rather than a Gaussian distribution (implied by choice of a least squares model). The choice of a Gumbel distribution has the benefit of a more conservative prediction of runout distances once a non-exceedance probability is chosen.

\section{ACKNOWLEDGEMENTS}

We wish to thank the Snow Avalanche Section of the British Columbia Ministry of Transportation and Highways for their support in funding this project. Also, special thanks go to the volunteer field assistants: B. Britten, B. Gould and P. Weckworth.

\section{REFERENCES}

Lied, K. and S. Bakkehøi. 1980. Empirical calculations of snow-avalanche run-out distance based on topographic parameters. 7. Glaciol., 26(94), 165-177.

McClung, D. M. and A. I. Mears. 1991. Extreme value prediction of snow avalanche runout. Cold Reg. Sci. Technol., 19(2), 163-175.

McClung, D. M., A. I. Mears and P. Schaerer. 1989. Extreme avalanche run-out: data from four mountain ranges. Ann. Glaciol., 13, 180-184.

Neter, J., W. Wasserman and G. A. Whitmore. 1982. Applied statistics. Second edition. Boston, MA, Allyn and Bacon.

The accuracy of references in the text and in this list is the responsibility of the authors, to whom queries should be addressed. 